\title{
Inflation, relative prices and nominal rigidities ${ }^{1}$
}

\author{
Luc Aucremanne, National Bank of Belgium, \\ Guy Brys, Peter J Rousseeuw and Anja Struyf, University of Antwerp, \\ Mia Hubert, University of Leuven
}

\begin{abstract}
This paper examines the distribution of Belgian consumer prices and its interaction with aggregate inflation over the period June 1976-September 2000. Given the fat-tailed nature of this distribution, both classical and robust measures of location, scale and skewness are presented. We found a positive short-run impact of the skewness of relative prices on aggregate inflation, irrespective of the average inflation rate. The dispersion of relative prices also has a positive impact on aggregate inflation in the short run and this impact is significantly lower in the subsample starting in 1988 than in the pre-1988 subsample, suggesting that the prevailing monetary policy regime has a substantial effect on this coefficient. The chronic right skewness of the distribution, revealed by the robust measures, is positively cointegrated with aggregate inflation, suggesting that it is largely dependent on the inflationary process itself and would disappear at zero inflation. These results have three important implications for monetary policy.

First, as regards the transmission of monetary policy, our results are in line with the predictions of menu cost models and therefore suggest that this type of friction can be an important factor behind the short-run non-neutrality of monetary policy. Second, as regards the design of robust estimators of core inflation, economic arguments based on menu cost models tend to highlight the importance of the absence of bias. We have proposed an unbiased estimator by taking the time-varying degree of chronic right skewness explicitly into account. Third, as regards the optimal rate of inflation, the chronic right skewness found in the data provides no argument against price stability, as it appears as an endogenous response of optimising price setters and would disappear when targeting a zero inflation rate. This conclusion contrasts sharply with the implications of the exogenously assumed downward rigidity of Tobin (1972), which would justify targeting a sufficiently positive inflation rate in order to facilitate the adjustment of relative prices. Our empirical findings contradict the latter type of downward rigidity, which implies a negative correlation between skewness and inflation. Therefore, the cross-sectional properties of Belgian inflation data do not provide strong arguments against a price stability-oriented monetary policy such as the one pursued by the Eurosystem.
\end{abstract}

\section{Introduction}

The aim of this paper is to study the cross-sectional properties of Belgian inflation data. The international literature on this issue highlights, broadly speaking, three not mutually exclusive aspects. First, many papers discuss the positive relationship between inflation on the one hand and the dispersion and/or asymmetry of relative prices on the other. Often these relationships have been interpreted as being symptomatic of nominal rigidities of one form or another. Ball and Mankiw's (1995) menu cost model has recently been the focal point of this strand in the literature. Second, in line with the findings of Bryan et al (1997), it is often documented that inflation data are fat-tailed and this motivates the stochastic approach to core inflation in which robust estimators of location are

\footnotetext{
Luc Aucremanne: National Bank of Belgium, Research Department (e-mail: luc.aucremanne@nbb.be); Guy Brys, Peter J Rousseeuw and Anja Struyf: University of Antwerp, Department of Mathematics and Computer Science (e-mail: gbrys@ua.ac.be); Mia Hubert: University of Leuven, Department of Mathematics. The authors would like to thank Emmanuel Dhyne, Philippe Moës, Alain Nyssens and Raf Wouters for comments on an earlier draft of this paper. The views expressed in this paper are those of the authors and do not necessarily reflect the views of the National Bank of Belgium.
} 
proposed. Third, in quite a few countries researchers found not only a considerable degree of frequently switching left and right skewness but, on average, also a tendency towards right skewness.

The latter characteristic of the data, which is for instance discussed in Roger (2000), raises two additional questions. The first question is whether this chronic right skewness results from an exogenous form of downward nominal rigidity in product markets, such as the one put forward in Tobin (1972), or whether it is endogenously generated as menu cost models suggest. These two sources of asymmetry have different, empirically testable implications for the relation between inflation and skewness: the first source implies a negative relation, whereas the second implies a positive relation. Distinguishing between these two sources of skewness is particularly relevant from a monetary policy perspective, as they have different implications for the optimal rate of inflation. In the case of an exogenous form of downward nominal rigidity, low inflation rates are harmful as they complicate the (downward) adjustment of relative prices. In the other event, low inflation is desirable, as it reduces the costs associated with changing prices, as well as the impact of monetary policy on the distribution of relative prices. The second question raised by the chronic right skewness is how to incorporate it in the construction of robust estimators of core inflation.

This type of analysis often uses the classical characteristics of location, scale, skewness and kurtosis. These measures are, however, very sensitive to outlying values. In this paper we will compare them with robust alternatives, not only for location, as is typically done in the core inflation part of this literature, but also for scale, skewness and tail weight. We will address the question of whether robust measures are applicable in this context, because inflation is often strongly influenced by outliers which are both correct and important. Overly strong robustness may downweight outliers too much and thus yield little sensitivity. Extending the use of robust estimators to the scale, skewness and tail weight of the distribution of inflation data is the main statistical contribution of our paper.

From an economic point of view, one may wonder what justifies downweighting outlying values in inflation data. After all, we all buy goods and services for which prices change dramatically. There is often some assumption about price stickiness underlying this treatment of outliers. In the flexible price benchmark, the classical dichotomy holds: inflation is a purely monetary phenomenon, independent of relative prices, which themselves are influenced by real determinants only. In that case it makes no sense to downweight outlying values in order to compute alternative (core) aggregate measures. With prices sticky in the short run, relative prices and inflation are no longer independent and causality goes in both directions. Relative price shocks - large shocks in particular - can affect aggregate inflation in the short run, thus temporarily masking the effect of the factors which are more relevant from a monetary policy perspective, such as the balance of supply and demand in the economy or the impact of inflation expectations. In such a setting, downweighting outliers aims at putting more weight on these factors. This provides the economic rationale for using robust estimators of location as core inflation measures, as Bryan and Cecchetti (1994) do on the basis of the menu cost model of Ball and Mankiw (1995).

In this paper we extend the argument to measures of scale and skewness and find that the robust alternatives are better suited to show the impact of these monetary policy-related factors on the distribution of relative prices. Using this type of measure, we found that aggregate inflation had a substantial impact on the dispersion of relative prices in Belgium. Moreover, they revealed endogenous chronic right skewness in the distribution of observed relative prices, which tends to increase with aggregate inflation and, according to our econometric results, would tend to disappear with zero inflation. This type of asymmetric price adjustment is what the menu cost model of Ball and Mankiw (1994) predicts, and we consider this as our main empirical result.

We obtained these results using readily available inflation data at a relatively high level of aggregation (a 60-item breakdown), whereas it is the standard view that intramarket rather than intermarket data are the appropriate dimension to uncover a causal relation running from the inflationary process to the distribution of relative prices. ${ }^{2}$ We owe this to the fact that we have used the data at the highest frequency available, ie one-month price changes, and that the cross-sectional properties were studied on the basis of robust measures of scale and skewness. As regards the corresponding classical measures, they allowed us to illustrate the causality in the other direction, ie from the distribution of relative price shocks to aggregate inflation.

2 See for instance Ball and Mankiw (1994), Lach and Tsiddon (1992) or Cecchetti and Groshen (2000) on this point. 
The remainder of the paper is structured as follows. Section 2 describes the Belgian inflation data and discusses the format in which we will investigate them. In Section 3, robust measures of location, scale and tail weight are proposed and used to detect the presence of outlying values in the data. Section 4 briefly compares the classical and robust measures of location and scale. Section 5 discusses the classical and robust measures of skewness, as well as the chronic right skewness which they reveal. Section 6 presents, for the classical and the robust measures of skewness and scale respectively, their relation with inflation and discusses the empirical findings against the background of menu cost models. Moreover, the results are interpreted in terms of what is known in the literature on the optimal rate of inflation as "grease" and "sand" effects. Section 7 presents a robust unbiased estimator of core inflation. Section 8 sets out the conclusions.

\section{Description of the data}

This study is based on Belgian monthly consumer price index (CPI) data for the period June $1976^{3}$ to September 2000, yielding a total of 292 months. For each month, we have aggregated price indices of 60 different product categories. The index of product category $i(i=1, \ldots, 60)$ at month $t(t=0, \ldots, 291)$ is denoted by $l_{i, t}$.

We started by transforming these data into percentage one-month price changes $\Pi_{i, t}(t=1, \ldots, 291)$, defined by:

$\prod_{i, t}=\frac{l_{i, t}}{l_{i, t-1}}-1$

As the aim was to interpret some of the results obtained in terms of sticky versus flexible price behaviour, the obvious approach was to use data at the highest frequency available.

Note that these price changes can also be seen as the first-order approximation of logarithmic price changes:

$\ln \left(\frac{I_{i, t}}{I_{i, t-1}}\right)$

Both approaches did indeed yield approximately the same results, including those related to the presence of chronic right skewness. This suggests that using percentage price changes instead of log price changes is not an important factor behind the chronic right skewness, as could have been expected on the basis of Roger (2000). The latter paper inspired us also to test the robustness of the results obtained by removing from the data set 10 product categories for which prices were obviously adjusting infrequently. These are categories which are mainly regulated by government or law, eg bread, tobacco and education. Our results - including the endogenous nature of the chronic right skewness - were only slightly influenced by this modification. Therefore, the paper presents the results for all 60 product categories.

Summarising, we can represent our final data set $\Pi_{i, t}$ with a matrix that consists of 291 rows (indicating the different periods) and 60 columns (for the product categories). A cross section contains the price changes of one particular month, and thus corresponds to one row of the data matrix. Additionally, we have taken account of the fact that each product category has a time-varying weight $w_{i, t}$, which is obtained by multiplying for each period $t$ its fixed Laspeyres-type weight $w_{i}$ by the change in its relative price between the base period and period $t$. The Laspeyres-type weights $w_{i}$ of the CPI reflect the importance of each category in total household consumption expenditure in the base period. Evidently, the weights satisfy $\sum_{i=1}^{60} w_{i, t}=1$ for all $t$. In so doing, the weighted mean of the 60 product-specific price changes $\Pi_{i, t}$ corresponds to aggregate inflation.

It was not possible to start at an earlier point in time, for instance during the low-inflation regime of the 1960s, for data availability reasons. 


\section{Detection of outliers}

In this section we will mainly show that the Belgian price changes contain a substantial amount of outlying values. For this, we will consider the cross sections and compute robust measures of tail weight for each of them. To show the importance of the tails of univariate data (as the cross sections are), we can use the classical measure of kurtosis. In general, kurtosis is said to characterise the fatness of the tails, or equivalently the tail weight, but it also reflects the shape of the density in the centre. Moreover, the classical measure of kurtosis is based on moments of the data set, and thus it is strongly influenced by outliers. Despite the fact that outliers determine the tail weight, we can construct robust measures to compute it. For this purpose, we first need a robust estimator of location and scale for univariate data. In general, we denote the sample by $x_{i}(i=1, \ldots, n)$ and the corresponding weights by $w_{i}$. As usual, the weights sum to 1 . Time subscripts are omitted to simplify notations.

\subsection{Robust measure of location}

A measure of location should estimate a value that characterises the central position of the data. The best known measure of location is the weighted mean or average, defined as:

$$
\bar{x}=\sum_{i=1}^{n} w_{i} x_{i}
$$

Note that with the data set we analyse, the weighted mean corresponds to observed inflation.

A typical robust measure of location is the median. It is defined by first sorting the observations from smallest to largest, and then taking the middle observation (for an even number of observations we take the average of both observations in the middle). Here, we need the weighted variant of the median. In general, all measures based on percentiles can be modified easily to their weighted version by filling in the weighted percentiles. That is the main reason why all robust measures presented in this paper are based on percentiles. ${ }^{4}$ For the $p \%$ weighted percentile, denoted by $Q_{p}$, we first sort the observations from smallest to largest, and then take the first value with a cumulative weight higher than $p \%$. The weighted median equals the $50 \%$ weighted percentile, or $Q_{0.50}$.

\subsection{Robust measure of scale}

Scale characteristics measure how "spread out" the data values are. The classical measure of scale is the standard deviation, which is given by:

$$
s=\sqrt{\frac{\sum_{i=1}^{n} w_{i}\left(x_{i}-\bar{x}\right)^{2}}{1-\sum_{i=1}^{n} w_{i}^{2}}}
$$

where $\bar{x}$ stands for the mean. ${ }^{5}$ The interquartile range or IQR is a robust measure of scale which, like the median, is based on percentiles and is easy to calculate. The (weighted) interquartile range is the distance between the $75 \%$ percentile $Q_{0.75}$ and the $25 \%$ percentile $Q_{0.25}$, or:

$I Q R=Q_{0.75}-Q_{0.25}$

\subsection{Robust measures of tail weight}

We propose six alternatives to the classical kurtosis. We will denote them with tail length and tail mass. The tail length measures are based on differences between the outlying observations and the

\footnotetext{
4 Initial work on other robust measures based on couples and triples of observations was abandoned precisely because it was not straightforward to construct them in weighted terms. Verbrugge (1999) presents a robust measure of skewness based on triples for unweighted inflation data. Brys et al (2002) also discuss some unweighted robust skewness measures based on percentiles, couples and triples.

5 Equation (3.2) is based on the unbiased sample moments of unequally weighted frequency distributions presented in Roger (forthcoming).
} 
median of the data, while the tail mass measures simply count the outliers. To distinguish the outlying values from the regular ones we use the following outlier rules:

- $\quad$ The percentile rule, where an observation is declared an outlier when it lies outside the interval:

$\left[Q_{p}, Q_{1-p}\right]$

for any $0<p<1$. Here, we consider two particular choices of $p$, namely $p=12.5 \%$ and $p=25 \%$.

- $\quad$ The general boxplot rejection rule defines outliers as points outside the interval:

$\left[\right.$ med $-\frac{3}{2} I Q R$, med $\left.+\frac{3}{2} I Q R\right]$

where med denotes the median. This criterion is based on the definition of the whiskers in the univariate boxplot (see Tukey (1977)). ${ }^{6}$

- The asymmetric boxplot rule. This rule is a special case of the bivariate bagplot in Rousseeuw et al (1999), which is a bivariate generalisation of the boxplot. Points are considered outlying when they lie outside the interval:

$$
\left[\text { med }-3\left(Q_{0.50}-Q_{0.25}\right) \text {, med }+3\left(Q_{0.75}-Q_{0.50}\right)\right]
$$

Now we can introduce the tail length measures. For any of the outlier rules, we define:

left tail length $=\sum_{i=1}^{n} w_{i}\left(\frac{m e d-\hat{x}_{i}}{I Q R}\right)$

where $\hat{x}_{i}$ denote the left outliers found by that specific outlier rule. Note that the median and IQR are computed on all observations, including the outliers. Using the percentile rule, we so obtain left tail length(125) and left tail length(250). The general boxplot rule and the asymmetric box plot (abp) rule lead to the tail length measures left tail length(box) and left tail length(abp). By replacing the left outliers with the right outliers in equation (3.7), and by using $\left(\hat{x}_{i}-\right.$ med) instead of (med- $\left.\hat{x}_{i}\right)$ in the numerator, we get right tail length(125), right tail length(250), right tail length(box) and right tail length(abp).

Next, we obtain measures of the (left) tail mass as the sum of the weights of the (left) outliers, ie:

left tail mass $=\sum_{i=1}^{n} w_{i} \theta_{i}$

where $\theta_{i}$ equals 1 if $x_{i}$ is a left outlier and 0 if not. This leads to left tail mass(box) and left tail mass(abp). Note that it makes no sense to consider left tail mass(125) or left tail mass(250) since these measures are always equal to $12.5 \%$ or $25 \%$, regardless of the data. Considering the right outliers, we obtain right tail mass(box) and right tail mass(abp).

\subsection{Results for Belgian inflation data}

All measures defined above were applied to the cross sections of the Belgian inflation data. In Graphs 1 and 2 the resulting time series are plotted by considering all 291 consecutive cross sections. On the plots, the scatter points of the different measures are depicted, together with a smoother (solid line). We have chosen to use a Lowess smoother, which is a robust scatter plot smoother. ${ }^{7}$ Lowess uses robust locally linear fits, by placing a window about each point and weighting the points that are inside the window so that nearby points receive the most weight.

\footnotetext{
6 Note that this interval corresponds approximately to $[\bar{x}-2 s, \bar{x}+2 s]$ in the case of the normal distribution.

7 See Cleveland (1979).
} 
Graph 1

\section{Left tail weight}
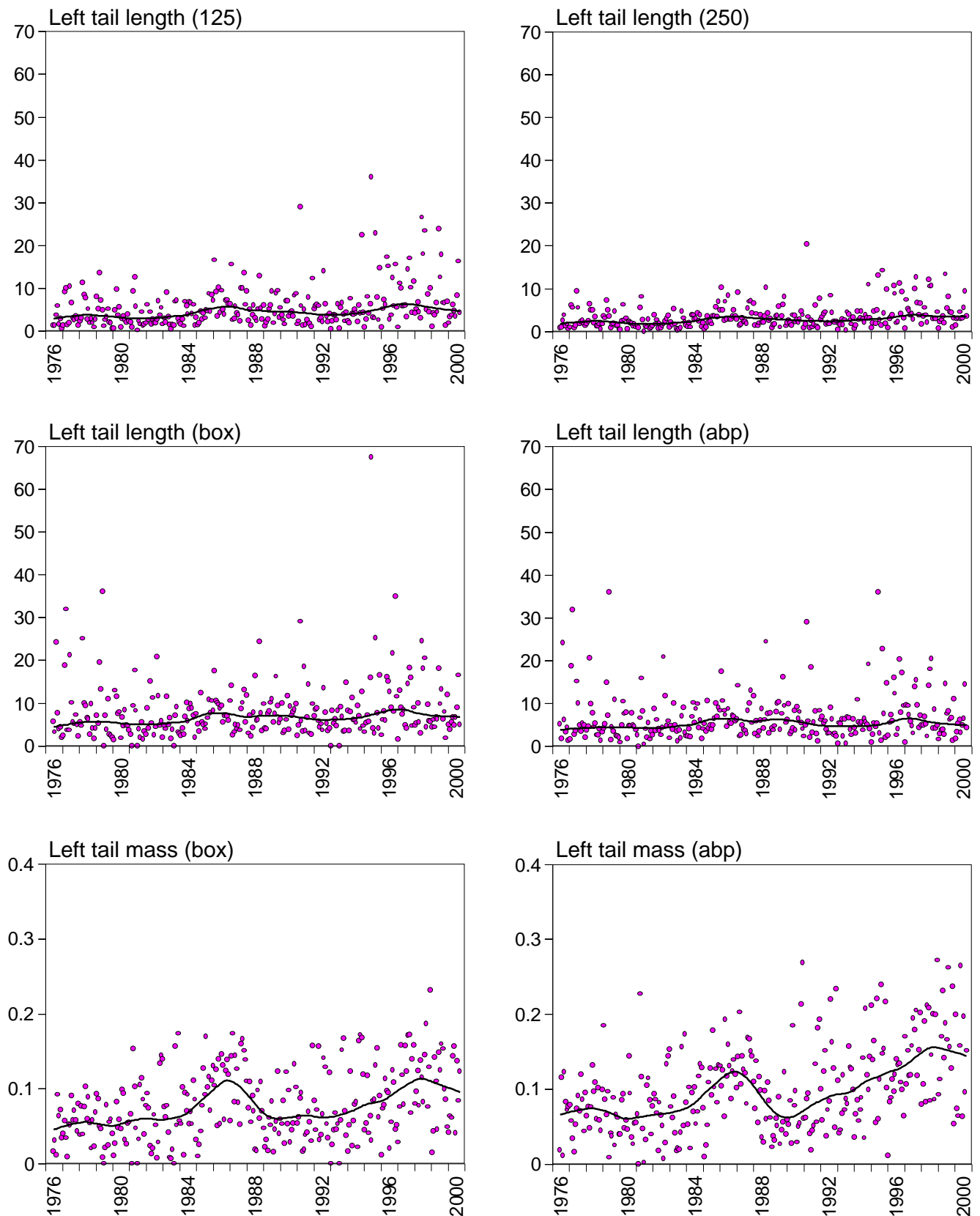
Graph 2

\section{Right tail weight}
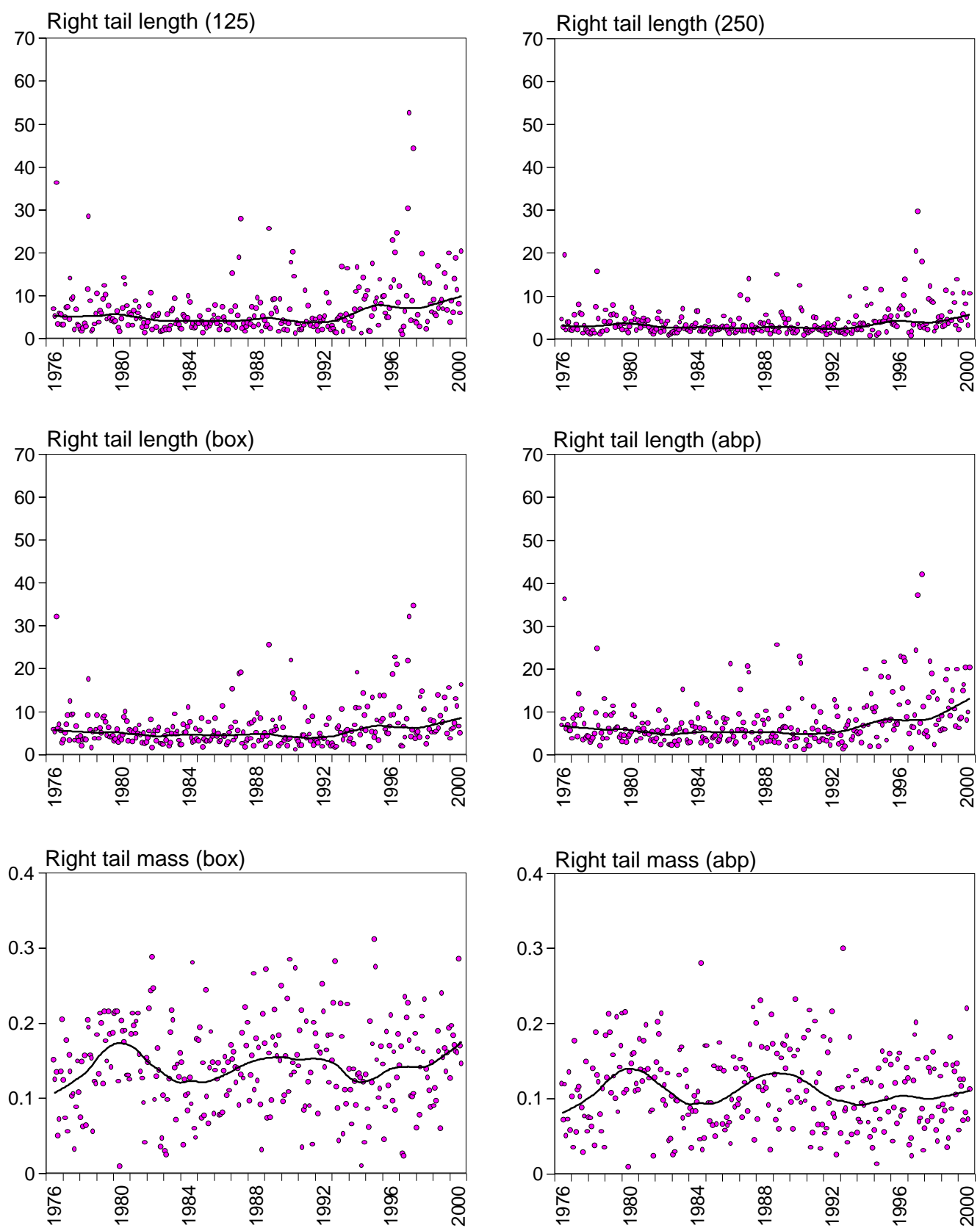

The tail mass(box) measures show substantial proportions of outliers and these proportions are, moreover, very volatile. This is why we will use robust measures of location, scale and skewness to analyse the data further on. Before doing so, we have a closer look at the tails. On the basis of the smoothed curves, left tail mass(box) amounted to roughly $5 \%$ at the beginning of the sample and increased to approximately $10 \%$ at the end of the sample. Right tail mass(box), in contrast, tends to oscillate around $15 \%$ during the whole sample. These observed tail weights are substantially in excess of those for the normal distribution, for which the corresponding tail mass(box) measures amount to 
$2.15 \%$ for each tail. This clearly illustrates the fat-tailed nature of Belgian inflation data, a finding which is in line with the results in the international literature on this issue. ${ }^{8}$ It should, however, be stressed that most of the international evidence is based on the classical kurtosis, which may for several reasons underestimate the importance of outliers. ${ }^{9}$

We interpret the fact that the smoothed curve indicates an upward tendency for left tail mass as a first piece of evidence against the existence of an exogenous form of downward nominal rigidity in Belgian product markets. Indeed, with aggregate inflation substantially lower in the second half of the period, the probability of having nominal price decreases in the left hand tail increases. If prices are effectively rigid downwards - ie if they cannot decrease in nominal terms for purely exogenous reasons - this should reduce left tail mass at the end of the period, whereas we observe exactly the opposite. The left tail length measures do not show a tendency to decrease over time either, thus confirming the conclusion made above.

The fact that right tail mass(box) tends to have larger values than the corresponding left alternative is a first indication of the existence of chronic right skewness, albeit apparently decreasing over time. A possible disadvantage of the general boxplot rejection rule is that it takes the left part of the data into account when defining a right outlier and vice versa. Using the asymmetric boxplot rule overcomes this problem. In so doing, we find that left tail mass $(a b p)$ increases and right tail mass(abp) decreases relative to their symmetrical alternatives, which can be seen as another indication of chronic right skewness. These asymmetrically constructed tail mass measures confirm the tendency for the lefthand tail to increase and the more stationary behaviour of the right-hand tail.

\section{Classical and robust measures of location and scale}

The classical and robust measures of location and scale are plotted in Graph 3. The robust alternatives were already used in the previous section to construct robust measures of tail weight. In this section we will compare them to their classical counterparts.

\subsection{Location}

As the use of robust measures of location for inflation data is well developed in the core inflation literature, we only give some brief comments when comparing the mean to the median. The interested reader is referred to other papers in this field for a deeper analysis. ${ }^{10}$ As the ADF tests reported in Table 1 fail to reject the null hypothesis of a unit root, both time series contain a stochastic trend. The smoothed curves in Graph 3 seem to confirm this conclusion. The median is substantially less volatile around its trend than the mean, thus confirming that using a robust estimator of location yields a substantial gain in efficiency in the case of a fat-tailed distribution. This could motivate the use of the median as a measure of core inflation statistically. The first robust core inflation measure, proposed by Bryan and Pike (1991), was indeed the median. Subsequently, a wide range of alternative robust estimators of core inflation have been proposed (see footnote 10 for references).

8 See, for instance, Bryan et al (1997), Roger (1997), Kearns (1998), Bakhshi and Yates (1999), Meyler (1999, 2001), Marques and Mota (2000), Aucremanne (2000), Vega and Wynne (2001), Knudsen and Nielsen (2002) and Roger (forthcoming).

9 See for instance Aucremanne (2000) on this so-called masking issue.

10 See for instance Bryan et al (1997), Roger (1997), Kearns (1998), Alvarez and de los Llanos Matea (1999), BIS (1999), Bakhshi and Yates (1999), Le Bihan and Sédillot (1999), Meyler (1999, 2001), Roger (2000), Aucremanne (2000), Landau (2000), Vega and Wynne (2001), Nielsen and Knudsen (2002) and Roger (forthcoming). 
Graph 3

Classical and robust measures of location and scale
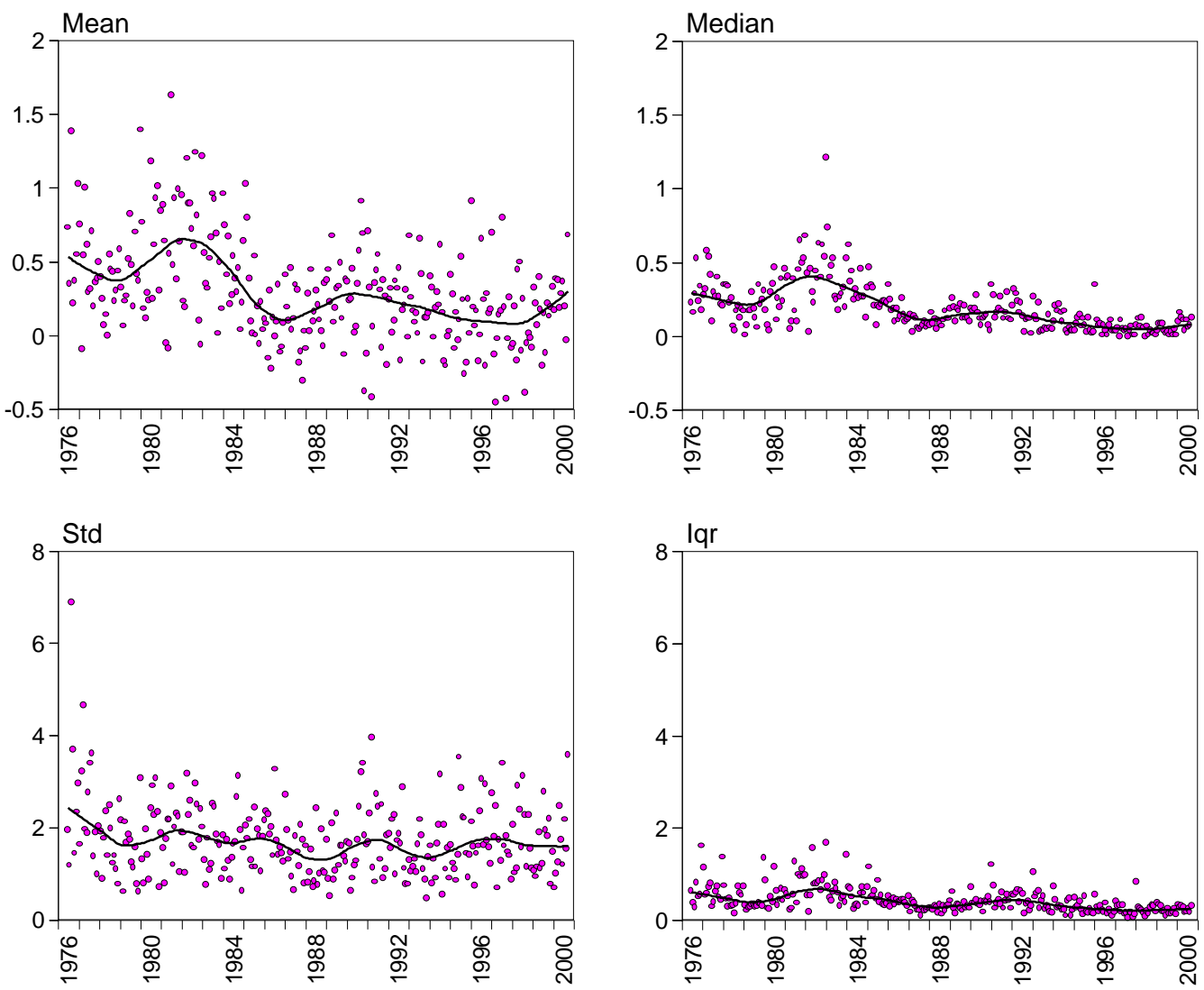

As can be seen from Table 2, the median is cointegrated with the mean, but with a coefficient $(0.5934)$ that is substantially less than one. In Graph 3 it can indeed be verified that the median tends to be lower than the mean. This is another indication of chronic right skewness in the Belgian inflation data and raises the question of constructing a core inflation measure which incorporates this characteristic of the data (see Section 7). As such, the median violates the first condition put forward in Marques et al (2000) for an ideal core inflation measure. It is said to be a biased estimator. Note also that the constant in the cointegration relation is very close to 0 , suggesting that the chronic asymmetry would disappear completely at zero inflation (see also Section 6).

\subsection{Scale}

Comparing the classical standard deviation with $I Q R$ indicates that relying on a robust alternative dramatically alters the characteristics of the measure of scale. According to the ADF tests in Table 1 , $I Q R$ contains a unit root whereas the classical measure appears as a stationary variable. Moreover, Graph 3 shows that the variability of $I Q R$ around its smoothed curve is substantially lower than the variability of the classical standard deviation. We owe this to the fact that the classical measure is dominated by the impact of outliers or, in economic terms, by large relative price shocks. In the absence of outliers, $I Q R$ would in contrast tend to be larger than the standard deviation (in the case of the normal distribution $I Q R \cong 1.35 \mathrm{std}$ ). Evidently, the impact of outliers on the classical measure of scale is magnified by squaring their deviations from the mean, as can be seen from equation (3.2). A more detailed analysis of the measures of scale and their relation with aggregate inflation is presented in Section 6. 


\section{Table 1}

Unit root tests for classical and robust measures of location, scale and skewness

(augmented Dickey-Fuller test statistic)

\begin{tabular}{l|c|c|c}
\hline & $\begin{array}{c}\text { With a constant in the } \\
\text { test equation }\end{array}$ & $\begin{array}{c}\text { Significance of the } \\
\text { constant - p-value }{ }^{2}\end{array}$ & Lag number $^{3}$ \\
\hline $\begin{array}{l}\text { Location } \\
\text { Mean }\end{array}$ & -1.74 & & 11 \\
Median & -1.58 & & 11 \\
Scale & -3.97 & 0.00 & 11 \\
Standard deviation & -1.74 & & 11 \\
IQR & -3.82 & 0.12 & 11 \\
Skewness & -5.80 & 0.02 & 11 \\
skew(class) & -2.55 & & 11 \\
dskew(class) & -3.44 & 0.00 & 11 \\
dskew(125) & -2.59 & & 11 \\
dskew(250) & & & 11 \\
meme & & & \\
\hline
\end{tabular}

${ }^{1}$ The $95 \%$ critical value for rejection of the null hypothesis of a unit root is -2.87 . Inclusion of a trend in the test equations for those variables for which the null of a unit root was not rejected did not change the results. In other words, they were not trend stationary either. ${ }^{2}$ Only reported when the null hypothesis of a unit root is rejected. ${ }^{3}$ Given the monthly frequency of the data, 11 lags were necessary to produce residuals without autocorrelation.

\section{Table 2}

\section{Cointegration of robust measure of location with actual inflation (mean)}

\begin{tabular}{|c|c|}
\hline & Median \\
\hline Lag number & 11 \\
\hline \multicolumn{2}{|l|}{ Cointegration equation $(\mathrm{CE})^{1}$} \\
\hline Constant & $\begin{array}{c}0.0002 \\
(0.01)\end{array}$ \\
\hline Mean & $\begin{array}{l}-0.5934 \\
(-10.54)\end{array}$ \\
\hline \multicolumn{2}{|l|}{ Trace statistic $^{2}$} \\
\hline $\begin{array}{l}\text { No CE } \\
\text { At most } 1 \text { CE }\end{array}$ & $\begin{array}{c}35.09 \\
4.70\end{array}$ \\
\hline \multicolumn{2}{|c|}{$\begin{array}{l}\text { Normalised cointegration coefficients, with the coefficient of the variable at the top of the column normalised to } 1 .{ }^{2} \text { The } \\
95 \% \text { critical value is } 19.96 \text { for rejection of the null hypothesis of no cointegration equation and } 9.24 \text { for rejection of the null } \\
\text { hypothesis of at most } 1 \text { cointegration equation. The cointegration rank and the specification of the deterministic components } \\
\text { of the model were determined jointly on the basis of the general test procedure discussed in Johansen (1992). However, } \\
\text { models having trends in the levels of the variables (constants in the VAR) were not considered. }\end{array}$} \\
\hline
\end{tabular}




\section{Classical and robust measures of skewness}

Skewness reflects the shape of the distribution. A symmetric distribution has zero skewness, a distribution which is asymmetric with the largest tail to the right has a positive skewness, and a distribution with a longer left tail has a negative skewness.

\subsection{Classical measures of skewness}

Normally the standardised, unitless measures of asymmetry (skewness) are used. The best known measure of skewness is the classical skewness, ${ }^{11}$ which is defined as:

$\operatorname{skew}($ class $)=\frac{\sum_{i=1}^{n} w_{i}\left(x_{i}-\bar{x}\right)^{3}}{\left(1-3 \sum_{i=1}^{n} w_{i}^{2}+w_{i}^{3}\right) s^{3}}$

However, we will consider destandardised measures of asymmetry as well. In this way skewness becomes dependent on scale, but this correlation does not bother us. Indeed, the economic models we rely on suggest that scale and skewness interact (see also Section 6). Ball and Mankiw (1995) show that scale magnifies the effect of skewness on inflation, while the asymmetric range of inaction in Ball and Mankiw (1994), which is a possible source of right skewness in the data, is also unscaled. All destandardised measures of asymmetry are expressed in some unit, and the robust measures have the same units as the data and the measures of location and scale. The latter will facilitate their use in the construction of an unbiased core inflation estimator in Section 7. The destandardised classical skewness is defined as:

dskew (class) $=\frac{\sum_{i=1}^{n} w_{i}\left(x_{i}-\bar{x}\right)^{3}}{1-3 \sum_{i=1}^{n} w_{i}^{2}+2 \sum_{i=1}^{n} w_{i}^{3}}$

\subsection{Robust measures of skewness}

A disadvantage of the classical measures of skewness is that they change dramatically when we introduce an outlier. The impact of outliers is even stronger than in the case of the mean and the standard deviation. On the other hand, skewness is supposed to measure the asymmetry of the observations, so we may not downweight outliers too heavily. The first robust alternative we propose is dskew(125), which is given by:

$\operatorname{dskew}(125)=\left(Q_{0.875}-Q_{0.50}\right)-\left(Q_{0.50}-Q_{0.125}\right)$

with $Q_{p}$ again the $p \%$ (weighted) percentile. The following measure is very similar, but it is based on other percentiles. We compute dskew(250) as:

$\operatorname{dskew}(250)=\left(Q_{0.75}-Q_{0.50}\right)-\left(Q_{0.50}-Q_{0.25}\right)$

Another measure of skewness can be obtained by standardising the data as:

$z_{i}=x_{i}-$ med

and then taking the first moment of these standardised observations which corresponds to the meanmedian difference, meme yielding:

meme $=\bar{z}=\sum_{i=1}^{n} w_{i} z_{i}$

Strictly speaking this measure is not robust, as it uses the mean. However, we consider it here as an alternative measure of skewness as it has, compared to the classical measures, the advantage that the influence of what happens in the tails is far less accentuated.

11 Equations (5.1) and (5.2) are based on the unbiased sample moments of unequally weighted frequency distributions presented in Roger (forthcoming). 


\section{3}

\section{Chronic right skewness}

We have applied both types of measures of skewness on the cross sections of the Belgian inflation data. The resulting time series are plotted in Graph 4. The classical measures of skewness show a substantial degree of frequently switching left and right skewness, which is a typical result in the

\section{Graph 4}

\section{Classical and robust measures of skewness}
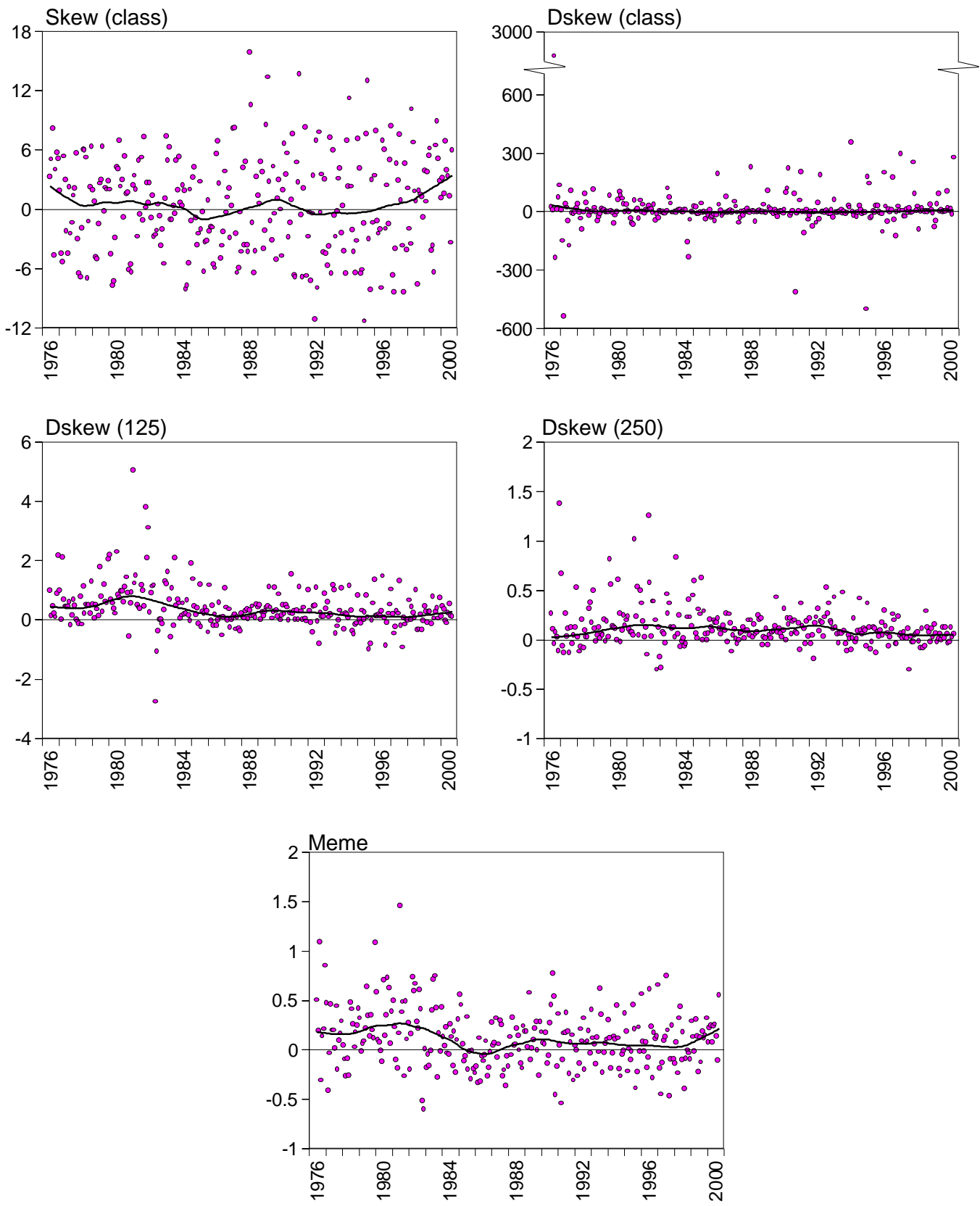
literature with regard to the analysis of inflation data. ${ }^{12}$ However, they do not show a clear tendency towards positive values. As for scale, the time series properties of the robust measures of skewness are fundamentally different from those of the classical ones. As the ADF tests in Table 1 indicate, the null hypothesis of a unit root in the classical measures was rejected at the $99 \%$ significance level. Moreover, the constant term in the test equation was not different from zero at the conventional significance levels for skew(class). For dskew(class) the constant was significant at the $95 \%$ level, but not at the $99 \%$ level. In addition, in this case the estimated value of the constant (11.14) is small relative to the variability observed in the series. Hence, the classical measures hardly reveal any form of chronic right skewness in a significant way, notwithstanding the fact that we provided evidence of a tendency towards right skewness in Sections 3 and 4.

In contrast, the robust measures dskew(125) and dskew(250) show a more pronounced tendency towards positive values. Hence, they better reveal the chronic right skewness of the data. The mean-median difference meme also shows such a tendency, although it takes negative values more frequently than the two other robust measures. We owe the latter to the fact that meme is in fact not robust. The null hypothesis of a unit root is rejected for dskew(250) at the $95 \%$ significance level, suggesting mean reversion around a significant positive constant. In contrast, for dskew(125) and meme, the null of a unit root is not rejected, suggesting a time-varying degree of chronic right skewness. Particularly in the second half of the sample, the tendency towards right skewness seems less pronounced, thus confirming the findings of Sections 3 and 4 . A chronic tendency towards right skewness is also found in several other countries, ${ }^{13}$ and some of these studies also mention that this tendency is less pronounced in the most recent period, when inflation is lower.

\section{Inflation and relative prices}

In this section we report our empirical results regarding the relationship between aggregate inflation and the classical and robust measures of scale and skewness, and interpret them against the background of menu cost models, as these have recently become the focal point in this literature. We start with an intuitive discussion of the main implications of these models.

\subsection{Menu cost models}

Menu cost models assume that changing prices involves a cost, which is fixed in the sense that it does not depend on the magnitude of the price change. Examples of this type of cost are changes to price lists, catalogues, advertising, etc. Simplifying the economy to one without trend inflation, where only zero mean relative price shocks occur, Ball and Mankiw (1995) show that the menu cost produces a symmetric range of inaction. Firms react only to large relative price shocks - responding equally to positive and negative shocks - for which the advantage of changing prices outweighs the menu cost.

As Graph 5 illustrates, ${ }^{14}$ symmetric distributions of relative price shocks do not affect aggregate inflation, as (large) price increases are exactly compensated by (large) price decreases. It is easy to verify that, in this case, increasing the variance of the (symmetric) distribution of relative price shocks has no effect on aggregate inflation either. However, things change when the distribution of relative price shocks is asymmetric. When these shocks are skewed to the right (left), large relative price increases (decreases) will no longer be compensated totally by large relative price changes in the

12 This property of the data is documented for several other countries in, for instance, Bryan et al (1997), Roger (1997), Kearns (1998), Alvarez and de los Llanos Matea (1999), Bakhshi and Yates (1999), Le Bihan and Sédillot (1999), Marques and Mota (2000), Aucremanne (2000), Meyler (2001), Vega and Wynne (2001), Knudsen and Nielsen (2002) and Roger (forthcoming).

13 See, for instance, Chatelain et al (1996) and Le Bihan and Sédillot (1999) for France, Roger (1997) and Roger (forthcoming) for New Zealand, Kearns (1998) for Australia, Marques and Mota $(2000)$ for Portugal, Meyler $(1999,2001)$ for Ireland, and Vega and Wynne (2001) for the euro area as a whole and for participating countries. In contrast, in the United States the distribution is symmetric (Cecchetti and Groshen (2000)).

14 The graph is based on Ball and Mankiw (1995). 
opposite direction, and aggregate inflation will increase (decrease) in the short run. In other words, the model predicts that inflation is positively related to the skewness of the relative price shocks in the short run and, by extension, also to the skewness of observed relative price changes. Increasing the variance of the skewed distributions - a phenomenon which can be measured by using destandardised measures of skewness - magnifies the impact of skewed relative price shocks on inflation. Ball and Mankiw have interpreted the positive correlation between inflation and the skewness of the distribution of relative prices as evidence in favour of menu cost models.

\section{Graph 5}

\section{The impact of the shape of the distribution of relative price shocks in a menu cost model without trend inflation}

Density functions of zero mean relative price shocks

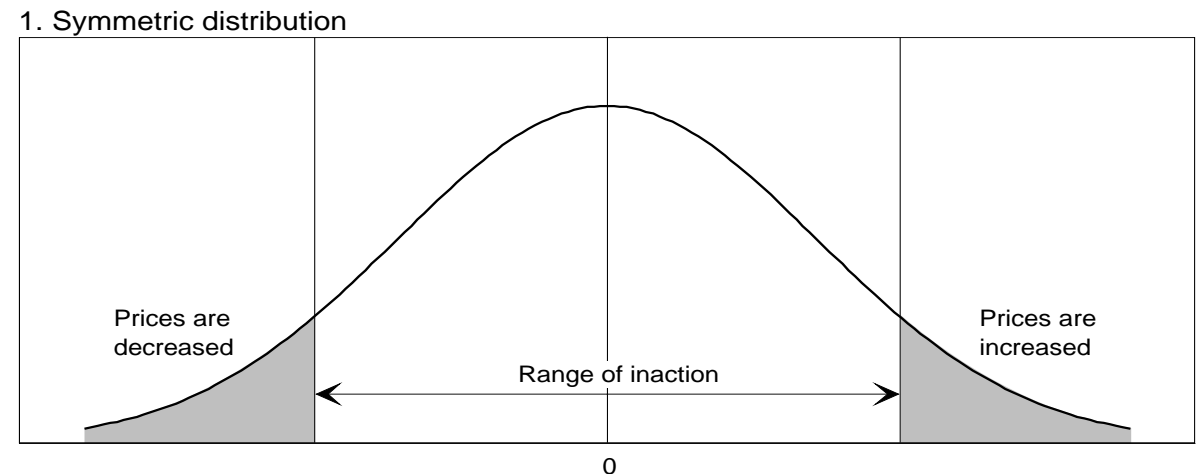

2. Skewed to the right

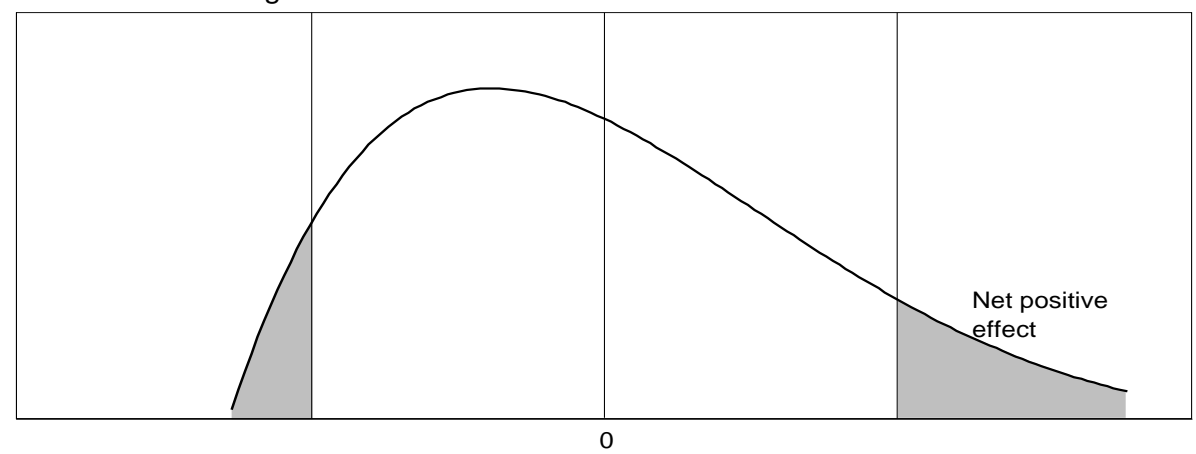

3. Skewed to the left

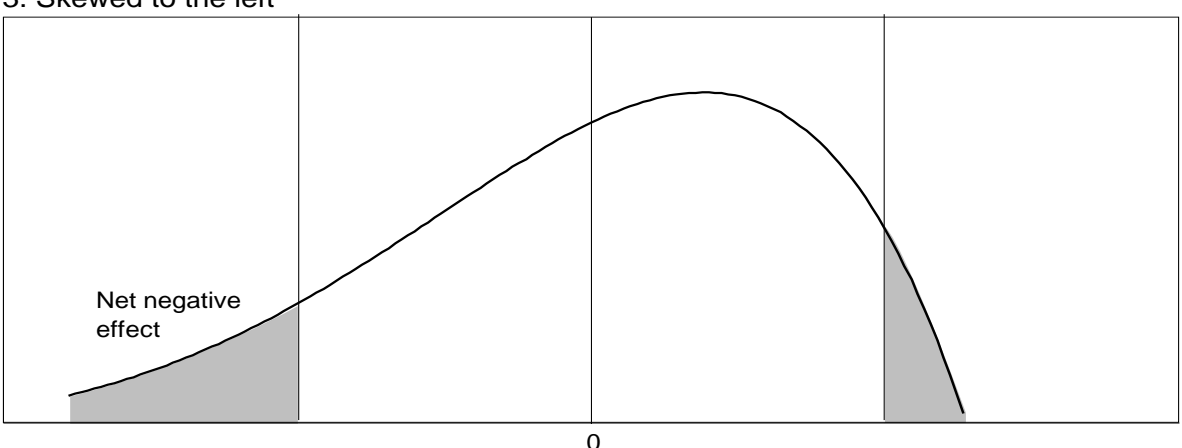


When trend inflation is introduced in an otherwise similar model, the optimising behaviour of price setters leads to an asymmetric range of inaction, as is illustrated in Graph 6. Trend inflation shifts the range of inaction endogenously leftwards: for a given absolute value of a relative price shock, an upward adjustment is more likely than a downward adjustment. The intensity of this shift depends on trend inflation. ${ }^{15}$ Intuitively, this asymmetry comes from the fact that trend inflation can lead to the desired relative price decreases even if nominal prices are not changed, whereas it magnifies the incentive to change nominal prices when a relative price increase is desirable.

\section{Graph 6}

\section{Introducing trend inflation in a menu cost model}

Density functions of zero mean relative price shocks

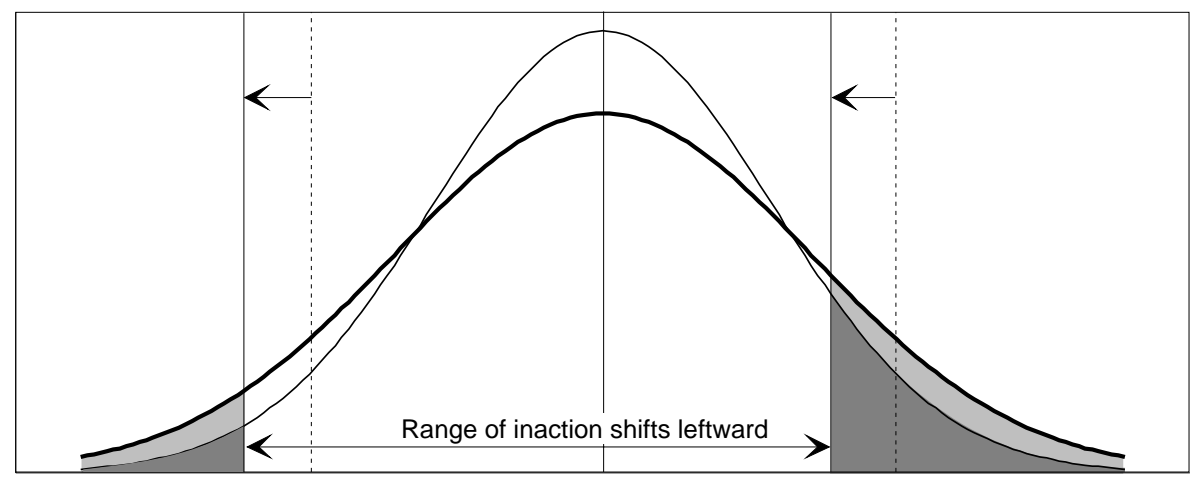

0

This has three implications for the relation between inflation and relative prices: (i) as is illustrated in Graph 6, increasing the variance of a symmetric distribution of relative price shocks now has a positive impact on observed inflation in the short run, and this impact increases with the intensity of the leftward shift of the range of inaction or, equivalently, with trend inflation; (ii) the impact of asymmetric price shocks on inflation in the short run is not fundamentally altered by the introduction of trend inflation in the model; and (iii) the model generates a tendency towards right skewness in the distribution of observed price changes, as price adjustment is more likely for positive relative price shocks than for negative shocks and this effect, too, increases with trend inflation. Clearly, for the latter effect, causality runs from trend inflation to the distribution of observed relative prices and this impact would disappear when targeting a zero inflation rate, in which case the range of inaction is again symmetric as in the first model.

Our findings with respect to the time series properties of the classical and the robust measures of scale and skewness respectively are not without consequences for their relation with aggregate inflation. They indicate that it is not appropriate to relate the classical measures of scale and skewness to inflation. Rather, they should be related to the first difference of inflation. This relation will be discussed in Section 6.2. With our data, relating the robust measures of scale and skewness to inflation must, in contrast, be done in a cointegration framework. The latter relations will be discussed in Sections 6.3 and 6.4.

15 For a formal derivation of this result, we refer to Ball and Mankiw (1994) or to Andersen (2000). 


\subsection{Using classical measures: relative prices affecting inflation}

Table 3 reports our regression results linking the first difference of observed monthly inflation with the classical measures of scale and skewness. Following De Abreu Lourenco and Gruen (1995), the sample was split into two subperiods to illustrate the role of trend inflation. According to the menu cost theory, the prevailing inflationary regime should particularly affect the estimated coefficient for scale. The first subperiod, running from 1976.09 to 1987.12 , was characterised by a substantially higher average inflation rate than the second subperiod, running from 1988.01 to 2000.09. For each subperiod a first regression is reported using the contemporaneous standard deviation, as well as two lags of this variable. The next equation adds the classical skewness and two lags as explanatory variables. Adding dskew(class) in a similar way did not yield significant coefficients for this variable. ${ }^{16}$ Table 3 gives the estimated coefficients, as well as the corresponding t-statistics. As the Durbin Watson statistics of the estimated regressions reveal the presence of autocorrelation, the t-statistics were calculated using the heteroskedasticity and autocorrelation consistent (HAC) covariance matrix estimator of Newey and West (1987).

Table 3

Regression results relating the change in inflation to the classical measures of scale and skewness

\begin{tabular}{|c|c|c|c|c|c|c|c|c|c|c|c|}
\hline & \multirow{2}{*}{$\begin{array}{c}\text { Constant } \\
\\
\\
C(1)\end{array}$} & \multicolumn{3}{|c|}{$\begin{array}{l}\text { Standard } \\
\text { deviation }\end{array}$} & \multicolumn{3}{|c|}{ skew(class) } & \multirow[t]{2}{*}{$\underset{\mathbf{R}^{2}}{\text { Adjusted }}$} & \multirow[t]{2}{*}{ DW } & \multicolumn{2}{|c|}{$\begin{array}{c}\text { Coefficient restrictions }^{1} \\
\text { p-value }\end{array}$} \\
\hline & & $\begin{array}{c}t \\
\mathrm{C}(2)\end{array}$ & $\begin{array}{l}t-1 \\
\mathrm{C}(3)\end{array}$ & $\begin{array}{l}t-2 \\
C(4)\end{array}$ & $\begin{array}{c}t \\
\mathrm{C}(5)\end{array}$ & $\begin{array}{l}t-1 \\
\mathrm{C}(6)\end{array}$ & $\begin{array}{l}t-2 \\
C(7)\end{array}$ & & & $\begin{array}{l}\mathrm{H}_{0} \\
\mathrm{C}(2)=-\mathrm{C}(3) \\
\mathrm{C}(4)=0 \\
\mathrm{C}(5)=-\mathrm{C}(6) \\
\mathrm{C}(7)=0\end{array}$ & $\begin{array}{l}\mathrm{H}_{0}: \\
\mathrm{C}(2)=0 \\
\mathrm{C}(3)=0 \\
\mathrm{C}(4)=0\end{array}$ \\
\hline $\begin{array}{l}\text { Period } \\
1976.09- \\
1987.12\end{array}$ & $\begin{array}{l}-0.073 \\
(-0.98)\end{array}$ & $\begin{array}{l}0.197 \\
(5.39)\end{array}$ & $\begin{array}{l}-0.186 \\
(-3.38)\end{array}$ & $\begin{array}{l}0.026 \\
(0.62)\end{array}$ & & & & 0.200 & 2.58 & 0.58 & 0.00 \\
\hline $\begin{array}{l}\text { Average } \\
\text { annual } \\
\text { inflation: } 5.3 \%\end{array}$ & $\begin{array}{l}-0.061 \\
(-1.02)\end{array}$ & $\begin{array}{l}0.189 \\
(4.88)\end{array}$ & $\begin{array}{l}-0.164 \\
(-3.77)\end{array}$ & $\begin{array}{l}0.008 \\
(0.26)\end{array}$ & $\begin{array}{l}0.039 \\
(4.94)\end{array}$ & $\begin{array}{l}-0.043 \\
(-4.08)\end{array}$ & $\begin{array}{l}-0.001 \\
(-0.08)\end{array}$ & 0.378 & 2.71 & 0.89 & 0.00 \\
\hline $\begin{array}{l}\text { Period } \\
1988.01- \\
2000.09\end{array}$ & $\begin{array}{l}0.109 \\
(1.36)\end{array}$ & $\begin{array}{l}0.079 \\
(1.53)\end{array}$ & $\begin{array}{l}-0.088 \\
(-1.99)\end{array}$ & $\begin{array}{l}-0.056 \\
(-1.39)\end{array}$ & & & & 0.045 & 2.60 & 0.27 & 0.12 \\
\hline $\begin{array}{l}\text { Average } \\
\text { annual } \\
\text { inflation: } 2.8 \%\end{array}$ & $\begin{array}{l}0.098 \\
(1.70)\end{array}$ & $\begin{array}{l}0.044 \\
(1.24)\end{array}$ & $\begin{array}{l}-0.060 \\
(-1.66)\end{array}$ & $\begin{array}{c}0.041 \\
(-1.38)\end{array}$ & $\begin{array}{l}0.024 \\
(6.65)\end{array}$ & $\begin{array}{l}-0.032 \\
(-7.20)\end{array}$ & $\begin{array}{l}0.002 \\
(0.53)\end{array}$ & 0.383 & 2.70 & 0.32 & 0.20 \\
\hline
\end{tabular}

Wald test.

All the estimated coefficients for the contemporaneous standard deviation (C(2)) and contemporaneous skew(class) $(\mathrm{C}(5))$ are positive. The estimated coefficients for the first lag of these variables $(C(3)$ and $C(6)$ respectively) have more or less the same magnitude in absolute value as the coefficient of the corresponding contemporaneous variable, but have systematically the opposite sign. All the coefficients for the second lag are statistically non-significant $(C(4)$ and $C(7)$ respectively). The null hypothesis which imposes these features as restrictions on the coefficients was not rejected by the first Wald test presented in Table 3. This clearly illustrates the short-run nature of the estimated equations: while having a clear impact on the change in inflation, the standard deviation and the skewness do not have a permanent effect on inflation. This suggests that these relations illustrate the impact of relative price shocks on inflation, which according to economic theory is short-lived. This would imply that, in the estimated regressions, causality is running from the standard deviation and

16 Results of this third type of regression are therefore not reported in Table 3. 
skew(class) to aggregate inflation. Overall, these results are in line with the predictions of menu cost models, outlined in the previous section. But do they really allow us to discriminate sticky from flexible price behaviour?

Finding a positive coefficient for contemporaneous skewness is not particularly relevant in this respect, as the traditional approach which interprets the classical mean-skewness correlation as evidence in favour of menu costs has recently been criticised on two grounds. In economic terms, Balke and Wynne (2000) showed that a flexible price general equilibrium model can generate this correlation as well. Statistically, Bryan and Cecchetti (1999) have attributed this result to the small-sample bias characterising this correlation in the case of fat-tailed distributions. ${ }^{17}$ However, the impact of the inflation regime on the estimated coefficients seems more relevant in this respect. Comparing the regression results for the two subperiods shows that the impact of the prevailing inflation regime is moderate for the coefficients of skewness. The inflation regime matters much more for the impact of scale, as the coefficients for the standard deviation are substantially reduced from the first to the second subsample, to the extent that they are no longer significant. The second Wald test presented in Table 3 clearly rejects the null hypothesis that all the coefficients of the standard deviation are zero in the first subsample, but not in the second subsample. In addition, this result is in line with the predictions of menu cost models and suggests an important role for trend inflation, which in principle is not crucial in flexible price models.

\subsection{Using robust measures: inflation affecting relative prices}

As shown in Table 4, using the robust measure dskew(125) reveals a clear positive cointegration relationship between asymmetry and inflation. Each percentage point of additional (monthly) inflation tends to increase dskew(125) by 1.5 percentage points. Moreover, the constant term in the cointegration relation is very small both in statistical and in economic terms, suggesting that the chronic right skewness would disappear at zero inflation. ${ }^{18}$ As such, the long-term behaviour of the chronic right skewness measured by dskew(125) seems to be an integral part of the inflationary process itself.

Also for dskew(250), the Johansen cointegration test reveals the existence of a positive cointegration relation with inflation, notwithstanding the fact that the ADF test reported in Table 1 suggests that dskew(250) is stationary. ${ }^{19}$ This measure of asymmetry tends to increase by 0.26 percentage points for each percentage point rise in (monthly) inflation. The constant in the cointegration relation for dskew(250) suggests the existence of some form of chronic right skewness which is independent of the inflationary process. The impact of this constant is, however, relatively small compared to the impact of inflation. Indeed, each $0.2 \%$ of additional monthly inflation (approximately $2.4 \%$ on a yearly basis) increases dskew(250) by the same amount as that resulting from the constant. This suggests that, relative to what has been observed historically, a substantial part of the chronic asymmetry measured by $d s k e w(250)$ disappears at zero inflation.

Summarising these results, for both robust measures of skewness there exists a positive long-run relation with aggregate inflation. Moreover, all of the asymmetry measured by dskew(125) and a substantial part of the asymmetry measured by dskew(250) would disappear at zero inflation. These findings confirm the result found for the mean-median relationship documented in Section 4. By uncovering this type of endogenous chronic right skewness, these results tend to provide more

17 The idea is that when samples are drawn from a fat-tailed distribution, they will tend to contain outliers (ie observations drawn from the left- or the right-hand tail), which influence both the mean and the classical skewness in the same direction. As a consequence, even for symmetric but fat-tailed distributions it is very likely that skewed samples will be drawn. In that event, the sampling may be an important source of the observed mean-skewness sample correlation, which does not necessarily characterise the distribution. Interesting in this respect is the observation that the coefficient of skewness is, for both periods, no longer significant when the regressions are estimated with the median instead of the mean as the inflation measure. Having no significant impact of skew(class) on the change in inflation beyond the first lag also illustrates the simultaneity in the mean-skewness correlation. See also the comments of Ball and Mankiw (1999) on this small-sample bias.

18 The sign of the constant term even suggests that the distribution would become slightly skewed to the left at zero inflation.

19 In the case of conflicting results, the Johansen test dominates the ADF test, implying that dskew(250) also contains a unit root. 
evidence in favour of menu cost models than that found on the basis of the classical measures only. Moreover, these results are qualitatively different from those of the previous subsection on the impact of skewness. Relating robust measures of skewness to aggregate inflation in a cointegration framework overcomes, by the very long-run nature of such a relation, the small-sample bias which typically characterises the contemporaneous correlation between inflation and skewness. The long-run nature of the relationship also suggests that monetary policy-related factors, such as the balance of supply and demand in the economy and inflation expectations, rather than relative price shocks, are the driving force. ${ }^{20}$ This also corroborates our presumption, put forward in the introduction, that downweighting outliers gives more weight to these monetary policy-related factors. The finding that causality runs from aggregate inflation to relative prices fits less well in a flexible price scenario.

\section{Table 4}

Cointegration of the robust measures of skewness and scale with actual inflation (mean)

\begin{tabular}{|c|c|c|c|}
\hline & dskew(125) & dskew(250) & IQR \\
\hline Lag number & 11 & 11 & 11 \\
\hline Cointegration equation $(\mathrm{CE})^{1}$ & & & \\
\hline Constant & $\begin{array}{r}0.0412 \\
(0.73)\end{array}$ & $\begin{array}{r}-0.0534 \\
(-2.55)\end{array}$ & $\begin{array}{r}-0.1790 \\
(-5.39)\end{array}$ \\
\hline Mean & $\begin{array}{r}-1.5037 \\
(-9.42)\end{array}$ & $\begin{array}{r}-0.2579 \\
(-4.38)\end{array}$ & $\begin{array}{r}-0.8088 \\
(-8.65)\end{array}$ \\
\hline Trace statistic $^{2}$ & & & \\
\hline No CE & 30.86 & 24.88 & 28.21 \\
\hline At most $1 \mathrm{CE}$ & 3.41 & 3.39 & 4.90 \\
\hline
\end{tabular}

1 Normalised cointegration coefficients, with the coefficient of the variable at the top of each column normalised to $1 .{ }^{2}$ The $95 \%$ critical value is 19.96 for rejection of the null hypothesis of no cointegration equation and 9.24 for rejection of the null hypothesis of at most 1 cointegration equation. The cointegration rank and the specification of the deterministic components of the model were determined jointly on the basis of the general test procedure discussed in Johansen (1992). However, models having trends in the levels of the variables (constants in the VAR) were not considered.

It is also important to note that this type of endogenous right skewness only reveals apparent downward nominal rigidity, as it would largely disappear at zero inflation. This differs substantially from the exogenously assumed downward nominal rigidity of Tobin (1972), which implies a negative rather than a positive relation between aggregate inflation and asymmetry, essentially on the basis of the same argument as the one we used in Section 3 to motivate a reduction of the left-hand tail. This difference is essential when the implications of our results for the optimal rate of inflation are examined, as is done in the next subsection.

\subsection{Grease and sand effects}

Tobin (1972) used the existence of exogenous downward nominal rigidity in labour markets to justify the statement that "higher prices or faster inflation can diminish involuntary, disequilibrium unemployment, even though voluntary, equilibrium labour supply is entirely free of money illusion" (see also Akerlof et al (1996) for a more recent treatment). The idea is that inflation relaxes the constraint that downward rigidity imposes on the adjustment of relative wages. According to this argument, inflation "greases" the wheels of the labour market. Extrapolated to product markets, the "grease" argument essentially states that, due to downward rigidities, there is insufficient relative price

20 In Sections 6.2 and 6.3 the causal direction was inferred from the short- and long-run nature of the respective relationships. This approach differs from the one followed in Hall and Yates (1998), where the concept of Granger causality was used. 
variability at low inflation rates, and that increasing inflation therefore leads to a more flexible economy and hence to a better economic performance. Maintaining the metaphor, inflation does, however, also have sand effects. The sand effect emphasises the fact that higher inflation can lead to unnecessary relative price variability which disrupts the allocative role that relative prices play in a market economy. These sand effects can result either from the staggered nature of price changes in the case of price stickiness or from a Lucas type of imperfect information, whereby higher and more variable inflation complicates the breakdown of observed nominal price changes into an aggregate and a relative component (Lucas $(1972,1973)$ ). Sand effects emphasise the excess of relative price variability at higher inflation rates and provide arguments in favour of a low inflation target.

Against this background, it is clear that the interpretation of the relation between inflation and relative price variability, which will be discussed below, is not straightforward, as a positive effect of inflation on relative price variability can be symptomatic of both grease and sand effects and, depending on which effect is dominant, leads to completely different policy implications as to the optimal rate of inflation. The complex nature of the link between inflation and relative price variability was already put forward in Fischer (1981).

Using the robust measure of scale $I Q R$, we do indeed find a strong positive cointegration relation between inflation and the dispersion of relative prices (see Table 4). The estimated impact of aggregate inflation on the dispersion of relative prices is again substantial, as a monthly inflation rate of $0.2 \%$ nearly doubles the dispersion that would prevail in the absence of inflation.

The literature on grease and sand effects ${ }^{21}$ emphasises the fact that intermarket data, ie the dimension of inflation data we are examining, are particularly relevant for finding grease effects, while sand effects should even occur among prices of identical goods and hence should also be present in intramarket data. As to sand effects, the dimension of the data is also important when trying to distinguish between the two possible sources of sand effects. Intermarket data are the most relevant for imperfect information induced sand effects, while staggering should also affect intramarket data.

Cecchetti and Groshen (2000) also point to the fact that sand effects should be symmetrical, while grease effects may have an asymmetric impact, as they facilitate downward adjustment in particular. With this in mind, our result that the chronic right skewness is largely endogenous, rather than resulting from presumed downward rigidities, considerably reduces the scope for substantial grease effects. Hence, we interpret the inflation- $I Q R$ relation as sand rather than as grease, and we conclude that the cross-sectional properties of Belgian inflation data do not provide strong arguments against a price stability-oriented monetary policy which targets a low inflation rate. Theoretically, this conclusion is in line with the implications of menu cost models. In Ball and Mankiw (1994), the endogenous asymmetry erases grease effects completely so that these authors find that, in their model, the optimal rate of inflation is zero, as it allows (i) a maximal reduction of sand effects and (ii) a reduction of the resources spent on changing prices. Empirically, our results appear in line with those reported in Yates (1998), where the absence of a negative relation between inflation and skewness is interpreted as evidence against the existence of specific downward rigidities. Suvanto and Hukkinen (forthcoming) found that declining prices were rather frequent in Finland during the period 1995-2001 and conclude from this that the assumption of downward rigidity of nominal prices cannot be generalised to all situations.

\section{An unbiased measure of core inflation}

In the statistical approach to core inflation, robust estimators of location are proposed on the basis of the fat-tailed nature of the distribution of price changes. Section 3 documented this characteristic of the data for Belgian one-month price changes. On the basis of the results presented in Sections 5 and 6 we found, moreover, that the distribution is not only fat-tailed but also skewed to the right. Given the chronic right skewness, symmetrically constructed robust estimators tend to underestimate aggregate inflation, as has been documented in Section 4 for the median. Several asymmetrically constructed

21 See, for instance, Cecchetti and Groshen (2000). 
robust estimators have been proposed to overcome this problem. ${ }^{22}$ They all have in common that the robust estimator is centred around a higher percentile than the $50 \%$ percentile and that this central percentile is essentially obtained by averaging over time some indicator of skewness. In so doing, this approach assumes a degree of chronic right skewness which is stable over time. However, by using robust measures we were able to uncover the time-varying and endogenous nature of the chronic right skewness in Belgian one-month price changes. This characteristic of the data presumably explains why some instability in the central percentile was found in Aucremanne (2000), when it was calculated for different periods, each of which was characterised by a different average inflation rate.

The use of robust estimators of location as measures of core inflation has also been motivated in economic terms by Bryan and Cecchetti (1994) on the basis of a variant of the (symmetric) menu cost model of Ball and Mankiw (1995). Since then, the economic rationale of robust estimators has, however, been criticised by several authors, mainly for two reasons.

First, as was emphasised above, the short-run mean-skewness correlation was found not to provide sufficient evidence in favour of menu costs. Second, even if menu costs or some other form of price stickiness do indeed exist, one should be careful in downweighting outliers. In that event, not only relative price shocks but also the inflationary process itself affects the distribution of relative prices. Hence, an outlier can be the result of a pure relative price shock, in which case downweighting this observation seems justified. Alternatively, it can also correspond to a price change induced by aggregate demand fluctuations, which are more relevant from a monetary policy perspective. In a context of infrequent adjustment of prices, this type of price change, too, will typically be large. This point was made in several papers, such as Zeldes (1994), Bakhshi and Yates (1999) and more recently in Aoki (2001) and in Mankikar and Paisley (2001). Finding an endogenous degree of chronic right skewness illustrates that this problem is not a purely theoretical issue, but has a clear practical relevance as well.

Against this background, it is our view that the chronic asymmetry found in the Belgian inflation data provides additional evidence in favour of menu cost models, on top of the evidence obtained on the basis of the classical mean-skewness correlation only. As such, this reinforces the economic rationale for the use of robust estimators of location, but at the same time it complicates their construction as the endogenous nature of the chronic right skewness should be taken into account. These economic arguments tend to put a lot of weight on the absence of bias in the estimator, whereas initially the focus was much more on the efficiency gain. In the case of skewed distributions, there is indeed a trade-off between efficiency and absence of bias. This point is illustrated, for instance, in Le Bihan and Sédillot (1999). We present a robust estimator of location below based on the median as a measure of core inflation, which is by construction unbiased and is nevertheless more efficient than the mean.

Our starting point is the first condition of Marques et al (2000) for an ideal core inflation measure, which provides an operational definition for an unbiased estimator. According to their terminology, a core inflation estimator is considered unbiased if cointegration with a unitary coefficient is found between actual and core inflation. In the previous sections, we provided evidence on two occasions that this was not the case for the median. First, in Section 4 we found a coefficient which is substantially less than one ( 0.5934 , to be precise) in the cointegration equation linking the median and the mean. Second, in Section 5 it was found that the mean-median difference meme is a non-stationary variable, even in a test equation incorporating a constant term. The latter finding illustrates clearly that fixing the bias is a more complicated issue than merely correcting for a constant term, as is sometimes suggested.

Our strategy is to link meme in a cointegration relation to one of the robust measures of (chronic right) skewness and to exploit this cointegration relation subsequently to construct an unbiased estimator of core inflation. In so doing, we found that meme was cointegrated with dskew(125) in the following way:

meme -0.3057 dskew $(125) \cong \mathrm{I}(0)$

By construction, this implies that the variable median +0.3057 dskew $(125)$ is cointegrated with a unitary coefficient with the mean (or, equivalently, with actual inflation). In consequence, this variable can be considered as an unbiased estimator of core inflation. The rationale of this approach is that, by

22 See, for instance, Chatelain et al (1996), Roger (1997), Kearns (1998), Aucremanne (2000), Marques and Mota (2000) and Meyler (1999, 2001). 
incorporating dskew(125), the median is corrected upwards in order to take account of the chronic right skewness of the distribution, which is, as emphasised above, time-varying and largely part of the inflationary process itself. Hence, the fraction of the mean-median difference which is attributable to the chronic right skewness is incorporated into the core inflation measure, while the latter ignores only the fraction of the mean-median difference which is influenced by what is happening far down in the tails.

As inflation data are often expressed as year-on-year growth rates, we decided to express the core inflation measure considered as 12-month price changes as well, by simply compounding the original one-month price changes of the last 12 months. A similar approach - robust estimation on the basis of one-month price changes and subsequent smoothing by compounding it over the last 12 months - is applied in the Bank of England (see Mankikar and Paisley (2001)), and was also followed in Aucremanne (2000). All in all, the proposed core inflation measure of period $t$, expressed in terms of 12-month price changes, corresponds to:

$\Pi_{s=0}^{11}\left[1+\left(\right.\right.$ median $_{t-s}+0.3057$ dskew $\left.\left.(125)_{t-s}\right)\right]-1$

\section{Graph 7}

\section{Unbiased robust estimator of core inflation}

Compounded results, percentage changes

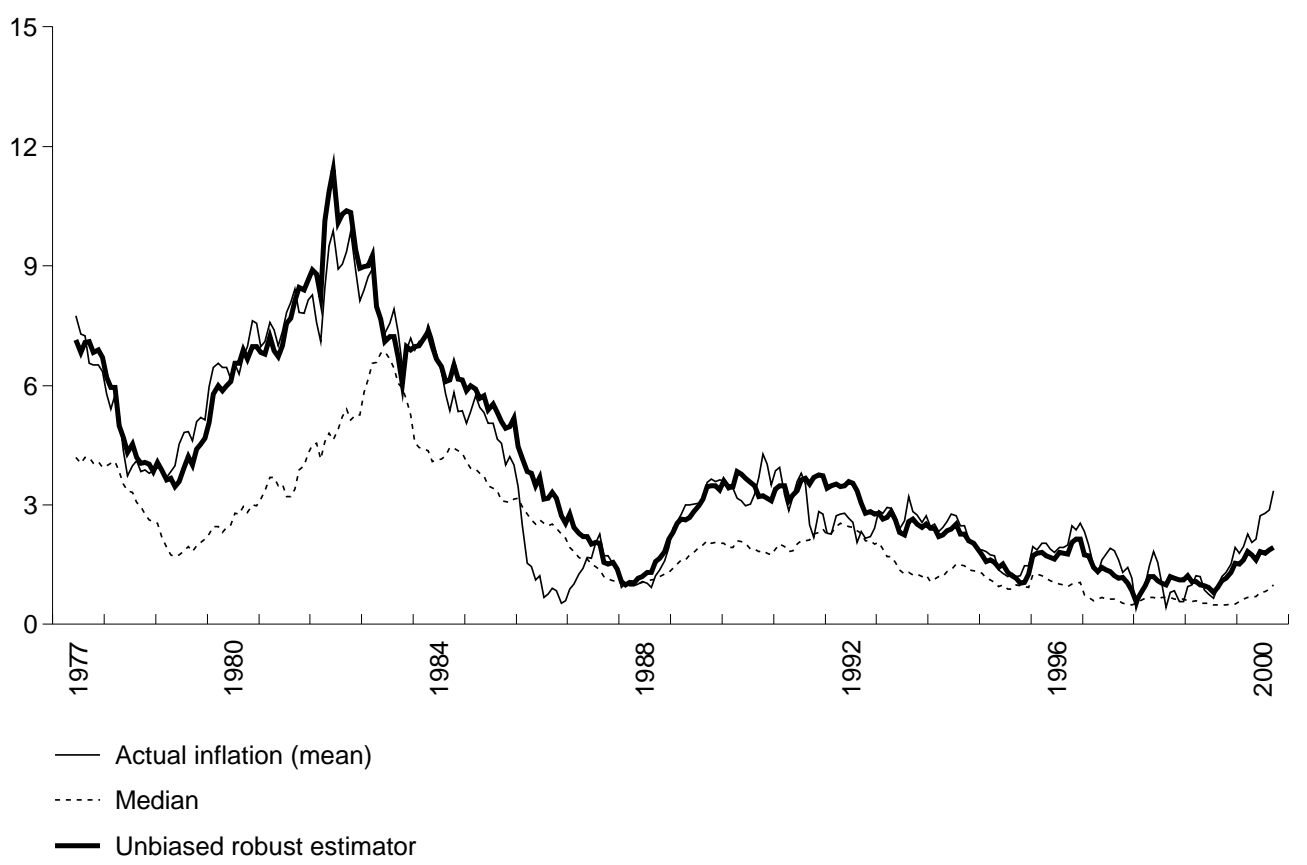

In Graph 7 the proposed estimator of core inflation is plotted together with the 12-month inflation rate and the median, which has been compounded in a similar way to obtain 12-month price changes as well. A comparison of the proposed core inflation measure with the median clearly illustrates the upward, but time-varying, correction made to the median, which makes the new estimator unbiased. But it also shows that the proposed core inflation measure is less smooth over time than the median, thus clearly illustrating the trade-off between absence of bias and efficiency. Despite this loss in efficiency relative to the median, the proposed core inflation measure remains smoother than actual 
inflation. ${ }^{23}$ Of course, smoothness is a desirable property of a core inflation measure. However, as the smoothness of the shocks underlying the (core) inflationary process, as well as the smoothness of their transmission into prices, is unknown, it is not clear a priori exactly how smooth the core inflation measure should be. The loss of smoothness compared to the median is therefore not necessarily a drawback. Indeed, it seems that it is compensated for by the fact that the proposed core inflation measure is more deeply embedded in economic theory, by trying to abstract only from relative price changes which are due to pure relative price shocks, but not from those which, in a context of infrequent price adjustment, are the result of the ongoing inflationary process itself. The proposed core inflation measure deviates particularly from observed inflation in 1976, when oil prices dropped sharply, and in 2000 , when oil prices increased substantially.

\section{Summary and conclusions}

In this paper we have studied the properties of the distribution of Belgian consumer prices for the period June 1976-September 2000, by using both classical and robust measures of location, scale, skewness and tail weight. The robust measures of tail weight showed clearly (i) the fat-tailed nature of the distribution, (ii) the short-run volatility of the tail weights, (iii) the tendency for the right-hand tail to dominate the left-hand tail, which points towards chronic right skewness, and (iv) the increase over time of the left-hand tail and the more stationary behaviour of the right-hand tail. The presence of outliers makes the classical measures of location, scale and skewness very volatile relative to the robust alternatives which have been used in the paper. Moreover, in the case of scale and skewness, the influence of the outliers on the classical measures erased any long-run time profile, whereas for their robust alternatives a stochastic trend was discovered, as was the case for the inflationary process itself. Finally, the classical measures of skewness hardly revealed any form of chronic right skewness, whereas the robust measures clearly bring this characteristic of the data, as well as its time-varying nature, into the picture.

In the econometric part of the paper, we discussed the relation between the distribution of relative prices and aggregate inflation. According to models with nominal rigidities - sticky price models in general, or more particularly menu cost models - the causality of this relation can run in two directions and both directions have been discussed in the paper. In particular, we were able (i) to describe the short-run impact of relative price shocks on aggregate inflation by using the classical measures of scale and skewness and (ii) to reveal the impact of the inflationary process on the distribution of observed relative prices by relating robust measures of scale and skewness to aggregate inflation in a cointegration framework.

Our main empirical results in this respect are threefold. First of all, we found a short-run impact of the skewness of observed relative prices on aggregate inflation, in line with Ball and Mankiw (1995). Second, it was found that the short-run impact of the dispersion of observed relative prices on inflation was substantially lower in the subsample starting in 1988 than in the pre-1988 subsample, suggesting that the prevailing monetary policy regime has a substantial effect on this coefficient. This result is in line with the model of asymmetric price adjustment of Ball and Mankiw (1994). Third, our further empirical results highlight the endogeneity of the asymmetry in the distribution of Belgian consumer prices. Indeed, it was found that the chronic right skewness was positively cointegrated with aggregate inflation. Moreover, we found little evidence of chronic right skewness not dependent on the inflationary process, suggesting that the asymmetry would disappear at zero inflation. Overall, these results are in line with the predictions of menu cost models and, importantly, they go beyond the contemporaneous mean skewness correlation. The latter has been criticised recently for not providing sufficient evidence in favour of menu costs on its own. The results presented are symptomatic of nominal rigidities, in the sense that prices are adjusted infrequently. However, they do not point in the direction of specific downward rigidities, other than those endogenously generated by the prevailing inflation rate.

23 As in Aucremanne (2000), smoothness has been measured here as the standard deviation of the first difference of the estimator considered. 
These results have three important policy implications.

First, as regards the transmission of monetary policy, they suggest that menu costs can be an important factor behind the short-run non-neutrality of monetary policy and the observed output and inflation dynamics. It should be taken into account that these models generate asymmetric output effects in consequence of the asymmetric nature of price adjustment to which they lead endogenously. As prices tend to adjust more slowly in the case of a negative shock than in the case of a positive shock, output is affected more when monetary policy is tightened than in the opposite event. According to menu cost models, this asymmetry depends on the prevailing inflation rate: it is more pronounced at higher rates of inflation and disappears when inflation is equal to zero. In this respect, it is interesting to remember that Peersman and Smets (2001) found larger monetary policy effects on output in recessions than in booms, not only in the euro area as a whole, but also in Belgium in particular. They did not attempt to distinguish between the various theories explaining this asymmetry. According to our results, menu costs could be a part of the story, at least for Belgium.

Second, as regards the design of core inflation measures, providing evidence in favour of menu cost models reinforces the economic rationale for the use of robust estimators of location, but at the same time it complicates their construction as the endogenous right skewness of the distribution of relative prices should be taken into account. These economic arguments tend to put a lot of weight on the absence of bias in the estimator. We have proposed an estimator which has this property, as it takes the time-varying degree of chronic right skewness explicitly into account.

Third, as regards the optimal rate of inflation, the chronic right skewness found in the data provides no argument against price stability, as it reveals only apparent downward nominal rigidity in product markets, which is an endogenous response of optimising price setters and which would disappear when targeting a zero inflation rate. The policy implication of this result contrasts sharply with the exogenously assumed downward rigidity of Tobin (1972), which would justify targeting a positive inflation rate in order to facilitate the adjustment of relative prices. In the absence of specific downward nominal rigidities, finding that aggregate inflation affects the distribution of relative prices rather provides an argument in favour of price stability, as it allows the impact of monetary policy on relative prices to be minimised. Clearly, this impact disrupts the allocative role prices play in a market economy. In the menu cost model of Ball and Mankiw (1994), the optimal rate of inflation is indeed equal to 0 . Evidently the analysis presented here does not take into account other factors which could justify a low but positive inflation target, such as downward nominal rigidities in labour markets, the zero bound for nominal interest rates and the presumably positive bias in aggregate inflation measurement. In any case, the cross-sectional properties of Belgian inflation data do not provide strong arguments against a price stability-oriented monetary policy such as the one pursued by the Eurosystem.

\section{References}

Akerlof, G A, W T Dickens and G L Perry (1996): "The macroeconomics of low inflation", Brookings Papers on Economic Activity, no 1, pp 1-59.

Alvarez, L J and M de los Llanos Matea (1999): "Underlying inflation measures in Spain", Bank of Spain Working Papers, no 11.

Andersen, T M (2000): "Nominal rigidities and the optimal rate of inflation", University of Aarhus, Department of Economics Working Paper, no 19.

Aoki, K (2001): "Optimal monetary policy response to relative-price shocks", Journal of Monetary Economics, no 1, pp 55-80.

Aucremanne, L (2000): "The use of robust estimators as measures of core inflation", National Bank of Belgium Working Papers - Research Series, no 2, March.

Bakhshi, H and T Yates (1999): "To trim or not to trim? An application of a trimmed mean inflation estimator to the United Kingdom", Bank of England Working Paper Series, no 97, July.

Balke, N S and M A Wynne (2000): "An equilibrium analysis of relative price changes and inflation", Journal of Monetary Economics, no 45-2, April, pp 269-92. 
Ball, L and N G Mankiw (1994): "Asymmetric price adjustment and economic fluctuations", Economic Journal, pp 247-62.

(1995): "Relative-price changes as aggregate supply shocks", The Quarterly Journal of Economics, no 1, February, pp 161-93.

(1999): "Interpreting the correlation between inflation and the skewness of relative prices: a comment on Bryan and Cecchetti", The Review of Economics and Statistics, no 91, May, pp 201-2.

Bank for International Settlements (1999): "Measures of underlying inflation and their role in the conduct of monetary policy", Proceedings of the workshop of central bank model builders, held at the BIS on 18-19 February 1999, Basel.

Bryan, M and S Cecchetti (1994): "Measuring core inflation", in N G Mankiw (ed), Monetary policy, Chicago: University of Chicago Press.

Bryan, M F and S G Cecchetti (1999): "Inflation and the distribution of price changes", The Review of Economics and Statistics, no 81, May, pp 188-96.

Bryan, M F and C J Pike (1991): "Median price changes: an alternative approach to measuring current monetary inflation", Federal Reserve Bank of Cleveland Economic Commentary, December, pp 1-4.

Bryan, M F, S G Cecchetti and R L Wiggins II (1997): "Efficient inflation estimation", NBER Working Paper Series, no 5793, October.

Brys, G, M Hubert and A Struyf (2003): "A comparison of some new measures of skewness", in R Dutter, P Filzmoser, U Gather and P J Rousseew (eds), Developments in robust statistics, International Conference on Robust Statistics 2001, Heidelberg.

Cecchetti, S and E Groshen (2000): "Understanding inflation: implications for monetary policy", NBER Working Paper Series, no 7482, January.

Chatelain, J B, I Odonnat and V P Sicsic (1996): "Construction sur longue période d'un indicateur d'inflation sous-jacente", Bank of France, mimeo.

Cleveland, W S (1979): "Robust locally weighted regression and smoothing scatterplots", Journal of the American Statistical Association, no 74, pp 829-36.

De Abreu Lourenco, R and D Gruen (1995): "Price stickiness and inflation", Reserve Bank of Australia Research Discussion Paper, no 9502, March.

Fischer, S (1981): "Relative shocks, relative price variability, and inflation", Brookings Papers on Economic Activity, pp 381-431.

Hall, S and A Yates (1998): "Are there downward nominal rigidities in product markets?", Bank of England Working Paper Series, no 80.

Johansen, S (1992): "Determination of the cointegration rank in the preference of a linear trend", Journal of Econometrics, no 52, pp 389-402.

Kearns, J (1998): "The distribution and the measurement of inflation", Reserve Bank of Australia Research Discussion Paper, no 10.

Lach, S and D Tsiddon (1992): "The behaviour of prices and inflation: an empirical analysis of disaggregated price data", Journal of Political Economy, no 100, April, pp 349-89.

Landau, B (2000): "Kerninflationsraten: ein Methodenvergleich auf der Basis westdeutscher Daten", Volkswirtschaftliche Forschungsgruppe der Deutschen Bundesbank - Diskussionspapier, no 4, August.

Le Bihan, $\mathrm{H}$ and F Sédillot (1999): "Interpreting and implementing indicators of core inflation - the case of France", Bank of France, Working Paper, no 69, December.

Lucas, R E (1972): "Expectations and the neutrality of money", Journal of Economic Theory, no 4, April.

(1973): "Some international evidence on output-inflation trade-offs", American Economic Review, no 63.

Mankikar, A and J Paisley (2001): "Core inflation measures in the UK", unpublished paper presented at a seminar on core inflation held at the ECB, Frankfurt, 30 May. 
Marques, C R and J M Mota (2000): "Using the asymmetric trimmed mean as a core inflation indicator", Bank of Portugal, Working Papers, no 6, October.

Marques, C R, P D Neves and L M Sarmento (2000): "Evaluating core inflation indicators", Bank of Portugal, Working Papers, no 3, April.

Meyler, A (1999): "A statistical measure of core inflation", Central Bank of Ireland Technical Paper Series, no 2, April.

(2001): "A statistical measure of core inflation", unpublished paper presented at a seminar on core inflation held at the ECB, Frankfurt, 30 May.

Newey, W and K West (1987): "A simple positive semi-definite, heteroskedasticity and autocorrelation consistent covariance matrix", Econometrica, no 55, pp 703-8.

Nielsen, H B and D Knudsen (2002): "Robust estimation of the expected inflation", National Bank of Denmark, Working Papers, March.

Peersman, $G$ and $F$ Smets (2001): "Are the effects of monetary policy in the euro area greater in recessions than in booms?", ECB Working Paper Series, no 52, March.

Roger, S (1997): "A robust measure of core inflation in New Zealand, 1949-96", Reserve Bank of New Zealand Discussion Paper Series, no 7, March.

- (2000): "Relative prices, inflation and core inflation", IMF Working Paper, no 58, March.

(forthcoming): "The distribution of consumer prices in New Zealand", IMF Working Paper.

Rousseeuw, P J, I Ruts and J W Tukey (1999): "The bagplot: a bivariate boxplot", The American Statistician, no 53, pp 382-7.

Suvanto, A and J Hukkinen (forthcoming): "Stable price level and changing prices".

Tobin, J (1972): "Inflation and unemployment", American Economic Review, no 62, pp 1-18.

Tukey, J W (1977): Exploratory data analysis, Addison-Wesley, Reading, MA.

Vega, J L and M Wynne (2001): "An evaluation of some measures of core inflation for the euro area", ECB Working Paper Series, no 53, April.

Verbrugge, $R$ (1999): "Cross-sectional inflation asymmetries and core inflation: a comment on Bryan and Cechetti", The Review of Economics and Statistics, no 81, May, pp 199-202.

Yates, A (1998): "Downward nominal rigidity and monetary policy", Bank of England Working Paper Series, no 82, August.

Zeldes, S P (1994): "Comment", in N G Mankiw (ed), Monetary policy, Chicago: University of Chicago Press. 